\title{
Cell Polarity in Bacillus subtilis: Effect of Growth Conditions on Spore Positions in Sister Cells
}

\author{
By G. DUNN AND J. MANDELSTAM \\ Microbiology Unit, Department of Biochemistry, University of Oxford, \\ Oxford $O X$ I $3 Q U$
}

(Received 27 July 1977)

\section{INTRODUCTION}

In bacilli, sporulation begins by formation of a septum at one end of the bacterium rather than at the centre. This raises the question of whether the cell should be regarded as an unpolarized structure in which the position of the spore is a result of a random event, or whether it possesses polarity which specifies that the spore is to be formed at one end of the cell rather than at the other. It is possible to test this because in cultures of Bacillus subtilis, as well as in those of other species, the two bacteria resulting from a division tend to remain attached, often for many hours. Furthermore, sporulation in such sister cells is highly synchronized (Dawes, Kay \& Mandelstam, I97I). It is then easy to determine by phase-contrast microscopy whether a spore has been formed proximally or distally in relation to the newest division septum. The possible patterns for spore positions in sister cells are as follows:

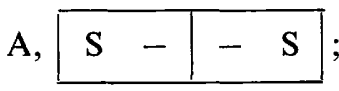

$\mathrm{B}$,
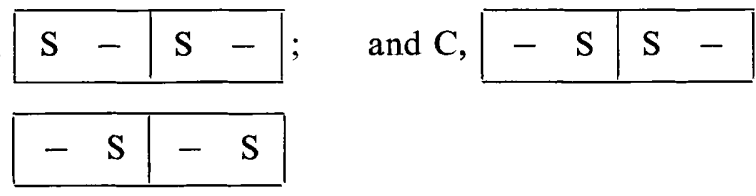

where $\mathrm{S}$ indicates a spore, and - indicates no spore.

If the probability that the spore will be formed at the proximal end is 0.5 , i.e. if the position of sporogenesis is determined by a random event, then each of the four possible combinations should be equally represented in the population. Since the two possibilities represented under B are indistinguishable, cell pairs of this type should constitute $50 \%$ of the population with $\mathrm{A}$ and $\mathrm{C}$ each accounting for $25 \%$. By contrast, if there is complete polarization in favour of one end, class B should be absent altogether. Such a result has been reported for spore distributions in Bacillus megaterium (Hitchins, 1975).

The experiments to be described show that the existence or non-existence of polarity in $B$. subtilis sporangia is determined by the medium in which vegetative growth occurs. In addition, experiments were carried out to determine whether polarity was correlated with the number of chromosome replication forks present in the cell at the onset of starvation.

\section{METHODS}

Strain and culture conditions. Bacillus subtilis $\mathbf{I} 68(\operatorname{trp} C 2)$ was grown either in a hydrolysed casein medium (CH) (Sterlini \& Mandelstam, I969), or in brain-heart infusion broth with $0.2 \%$ yeast extract (BHIB) (Difco). Cultures were harvested while in exponential growth $\left(0.25 \mathrm{mg} \mathrm{dry} \mathrm{wt} \mathrm{ml}^{-1}\right)$ and sporulation was induced by transferring the cells to a resuspension medium containing glutamate, tryptophan and inorganic ions (Sterlini \& Mandelstam, 1969). Incubations in the growth media and in the sporulation medium were either at 37 or $42^{\circ} \mathrm{C}$ as specified. 
Microscopy. The intracellular positions of phase-bright spores were scored in sister cells 6 to $8 \mathrm{~h}$ after resuspension.

DNA estimation. DNA was estimated by the method of Burton (1956).

Cell number estimation. Cell numbers were determined using a Coulter counter (model ZF), as described previously (Dunn, Torgersen \& Mandelstam, 1976).

\section{RESULTS}

Distribution of spore positions in sister cells after growth in $\mathrm{CH}$. Bacteria were grown in $\mathrm{CH}$ at $37^{\circ} \mathrm{C}$ and then transferred to resuspension medium also at $37^{\circ} \mathrm{C}$. The distribution of spore positions was measured $7 \mathrm{~h}$ after resuspension, at which time more than $80 \%$ of the cells were still in pairs. The following counts were obtained from 223 pairs (i.e. 446 cells): A, I4I (63\%); B, $67(30 \%)$; and C, I5 (7\%). The total number of cells in which a spore appeared at a distal end is the sum of all those in class $\mathrm{A}$ and half of those in class $\mathrm{B}$, i.e. $282+\left(\frac{1}{2} \times 1_{34}\right)=349$, or $78 \%$ of the total. The observation that under these conditions 75 to $80 \%$ of spores are formed at the distal end was confirmed in a number of experiments in which the scoring was done independently by several individuals.

Effect of sister cell separation on pattern of spore positions. The proportion of B. subtilis sporangia that persist as linked sister cells during starvation varies from day to day. Chains of cells are invariably formed soon after transfer to resuspension medium. Then, as sporulation proceeds, there is a tendency for the chains to break up. It could, therefore, be argued that the results are due to a decrease in 'stickiness', produced for some unknown reason, whenever a spore is generated in the proximal position. However, in the experiments already described only $20 \%$ of the sporangia were free, and even if all of these single sporangia had been exclusively derived from cell pairs of either class B or class $\mathrm{C}$ it would still be insufficient to upset the conclusion that spore formation occurs preferentially at the distal end - though the estimate of the degree of polarization would be different.

Nevertheless, to check this point counts were also done on days when the incidence of single cells was very high (about $90 \%$ ); the relative counts did not differ significantly from those obtained previously.

Effect of temperature on pattern of spore positions. In the first experiments incubations in both the growth and the sporulation media were carried out at $37^{\circ} \mathrm{C}$. The effect of temperature was examined by increasing the sporulation temperature to $42{ }^{\circ} \mathrm{C}$. This did not affect the incidence of distal spores, nor was there any significant effect produced by raising the growth temperature to $42^{\circ} \mathrm{C}$, although growth and sporulation were both accelerated at $42^{\circ} \mathrm{C}$.

Effect of growth medium on pattern of spore positions. We considered the possibility that the polarization within the sporulating cell might be influenced by the number of chromosome replication forks at the time of resuspension. We therefore grew the bacteria in BHIB in which the doubling time is 25 to $30 \mathrm{~min}$, compared with 40 to $45 \mathrm{~min}$ in $\mathrm{CH}$. An increase in the growth rate of the culture could be expected to increase the number of replicating forks in the chromosomes (Cooper \& Helmstetter, I968), and perhaps change the subsequent pattern of chromosome segregation on termination of the final round of replication after resuspension.

Bacteria were grown in BHIB at $42{ }^{\circ} \mathrm{C}$, and then transferred to the sporulation medium at the same temperature. The use of this growth medium resulted in the complete disappearance of the polarity effect; only $5 \mathrm{I} \%$ of the sporangia contained spores at their distal ends. Similar changes in polarity as a result of changing the growth medium have been observed in cultures of Bacillus cereus (Hitchins, 1976).

The next step was to establish how long growth had to be maintained in BHIB to destroy the polarity effect. Bacteria were therefore grown first in $\mathrm{CH}$ for many generations at $42^{\circ} \mathrm{C}$, i.e. from a small inoculum to a density of $0.25 \mathrm{mg} \mathrm{ml}^{-1}$. The culture was centrifuged and the bacteria were suspended to the same density in BHIB. One portion was removed immediately and the bacteria were transferred to resuspension medium for sporulation. Further portions 

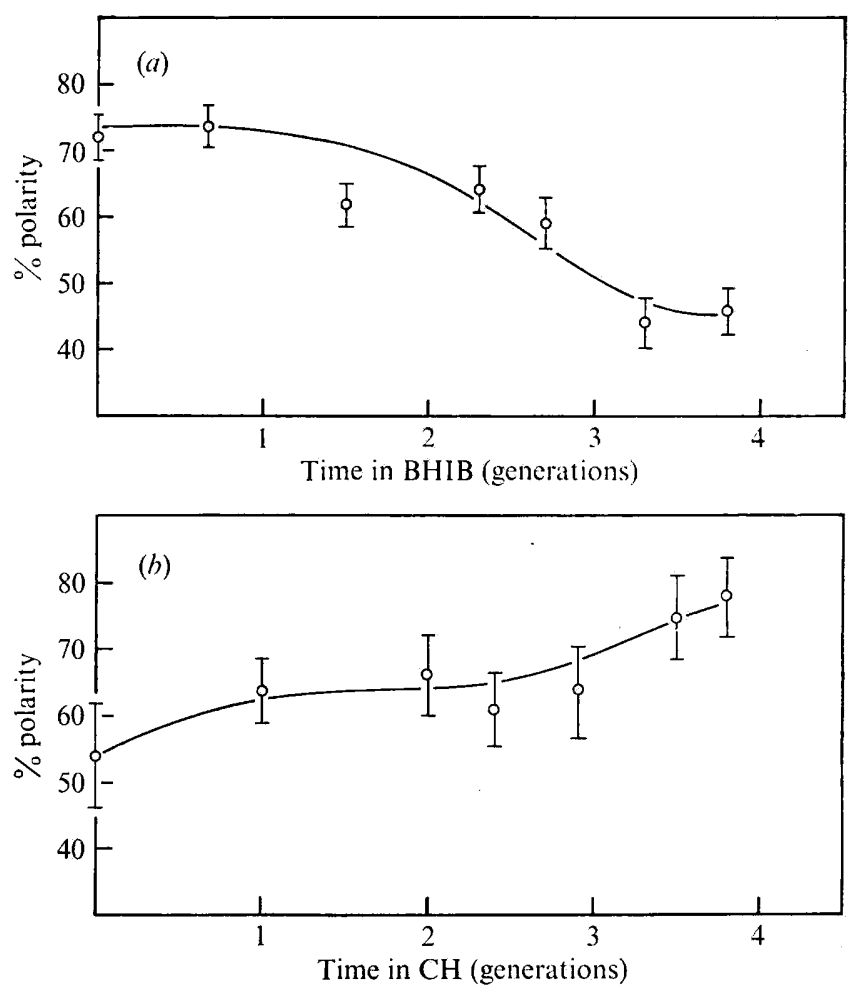

Fig. I. Effect of medium changes on polarity in Bacillus subtilis. Bacteria were first grown in either $\mathrm{CH}$ or BHIB for many generations at $42{ }^{\circ} \mathrm{C}$. The cultures were then centrifuged and the bacteria were suspended to the same density in the other medium. One portion was removed from each of these cultures and bacteria were transferred to resuspension medium for sporulation. Further portions of each culture were diluted 2-, 4-, 8-, I6-fold etc. in the relevant new medium. The diluted cultures were grown at $42{ }^{\circ} \mathrm{C}$. As each attained a density of about $0.25 \mathrm{mg} \mathrm{ml}^{-1}$, it was centrifuged and the bacteria were placed in resuspension medium for sporulation. The patterns of spore positions were determined $6 \mathrm{~h}$ after the induction of sporulation, and the proportion of cells with spores at their distal ends (\% polarity) was then estimated. (a) Change in polarity after transferring the cells from $\mathrm{CH}$ to BHIB (I50 pairs scored for each point). (b) Change in polarity after transferring the cells from BHIB to $\mathrm{CH}$ (600 pairs scored for each point). In each graph the error limits are given by $\pm \mathrm{I} \cdot 96 \sqrt{P(100-P) / N}$, where $P$ is the estimated \% polarity, and $N$ the total number of pairs scored.

of the culture were diluted 2-, 4-, 8-, I6-fold etc. with BHIB. These diluted cultures were grown at $42{ }^{\circ} \mathrm{C}$. As each attained a density of about $0.25 \mathrm{mg} \mathrm{ml}^{-1}$, it was centrifuged and the bacteria were placed in resuspension medium for sporulation. The patterns of spore positions were determined $6 \mathrm{~h}$ after the induction of sporulation. At least 150 cell pairs were counted for each sample.

The portion of cells exhibiting spores in the distal position was, as before, taken to comprise all those in class A and half of those in class B. The initial value, for cells that had just been grown in $\mathrm{CH}$, was about $73 \%$. This value fell during growth in BHIB and was about $45 \%$ after four generations (Fig. I $a$ ).

Experiments of the reverse type were then done, i.e. bacteria grown in BHIB for many generations were transferred to $\mathrm{CH}$ and tested periodically to establish their sporulation pattern. As expected, after growth in BHIB the bacteria were unpolarized, and the acquisition of polarization, like its loss, took place over several generations (Fig. $\mathrm{I} b$ ).

DNA synthesis after the onset of starvation. The amount of DNA in resuspended cultures was also measured. Bacteria were grown in $\mathrm{CH}$ or BHIB, resuspended in sporulation medium, 
and then the amount of DNA in these cultures up to $4 \mathrm{~h}$ after resuspension was determined. The number of bacteria in each of the cultures was also determined so that the amount of DNA per sporangium could be estimated. This was done because when sporulation has been induced, chromosome replications that are in progress go to completion, the cell divides, and the daughter cells then sporulate (Dawes et al., 1971). We assumed that the fastergrowing cells in BHIB (mean generation time about $30 \mathrm{~min}$ ) would contain more replication forks than those in $\mathrm{CH}$ (mean generation time about $40 \mathrm{~min}$ ) and that the increase in DNA would reflect this. In fact the DNA content in both cultures increased by about $40 \%$ to yield sporangia containing about $\mathrm{I} \cdot \mathrm{I} \times 10^{-8} \mu \mathrm{g}$, which is equivalent to that contained in two complete chromosomes (Dennis \& Wake, I966). We have no explanation for this result.

\section{DISCUSSION}

These results indicate that polarity in starving cells depends on the previous history of those cells. After resuspension, those grown in $\mathrm{CH}$ produce prespore septa which are predominantly at the distal end of the cell, while in those grown in BHIB the spore positions are randomly distributed. Although cells growing in BHIB presumably contain more replicating forks in their chromosomes, since they are growing faster, this does not appear to be the controlling factor in the determination of cell polarity. That this is so is indicated by the kinetics of changes in cell polarity after transfer of bacteria from one growth medium to the other. It takes about four generations for the polarity to change to that characteristic of the new growth medium, a period which appears to be far too long to be explained by cellcycle mediated phenomena. After growth in either medium, nuclear segregation and cell division result in the formation of sporangia containing two chromosomes, and there is no reason to believe that the mechanisms of nuclear segregation differ in the two situations. It is necessary, therefore, to seek some other determining factor in the control of the positioning of the prespore septum.

It is possible under certain conditions to detect polarity in the $B$. subtilis wall using phage SP50 as a marker (Archibald \& Coapes, 1976). A similar type of polarity, presumably associated with a particular structure or conformation in the wall, may determine the position of the prespore septum. If it does, there is an implied difference between the structure of walls in bacteria grown in $\mathrm{CH}$ and those grown in BHIB. Furthermore, it is known that wall turnover occurs at about $10 \%$ per generation (Pooley, $1976 a, b$ ). On this basis one would expect that after bacteria are transferred from one growth medium to another it would take several generations before the whole population had acquired or lost the structures that determine spore position.

We are grateful to Mrs Dawn Torgersen and Miss Prima Dunn for technical help and to Dr M. Young and Dr D. Kay for helpful discussions and for independent determinations of the distribution of spore positions. This work was supported by the Science Research Council.

\section{REFERENCES}

Archibald, A. R. \& Coapes, H. E. (1976). Bacteriophage SP50 as a marker for cell wall growth in Bacillus subtilis. Journal of Bacteriology 125, I 195-I 206.

Burton, K. (1956). A study of the conditions and mechanism of the diphenylamine reaction for the colorimetric estimation of deoxyribonucleic acid. Biochemical Journal 62, 315-323.

Cooper, S. \& HelmstetTer, C. E. (1968). Chromosome replication and the division cycle in Escheri- chia coli $\mathrm{B} / \mathrm{r}$. Journal of Molecular Biology $\mathbf{3}$, 519-540.

Dawes, I. W., Kay, D. \& Mandelstam, J. (I97I). Determining effect of growth medium on the shape and position of daughter chromosomes and on sporulation in Bacillus subtilis. Nature, London 230, 567-569.

Dennis, E. S. \& WaKe, R. G. (I966). Autoradiography of the Bacillus subtilis chromosome. Journal of Molecular Biology 15, 435-439. 
Dunn, G., Torgersen, D. M. \& Mandelstam, J. Pooley, H. M. (1976a). Turnover and spreading of (1976). Order of expression of genes affecting septum location during sporulation of Bacillus subtilis. Journal of Bacteriology x25, 776-779.

Hitchins, A. D. (1975). Polarized relationship of bacterial spore loci for the 'old' and 'new' ends of sporangia. Journal of Bacteriology 121, 518523.

Hitchins, A. D. (1976). Patterns of spore location in pairs of Bacillus cereus sporangia. Journal of Bacteriology 125, 366-368. old wall during surface growth of Bacillus subtilis. Journal of Bacteriology 125, I I $27-1$ I 38.

Pooley, H. M. (1976b). Layered distribution, according to age, within the cell wall of Bacillus subtilis. Journal of Bacteriology 125, I I39-I I47.

Sterlini, J. M. \& Mandelstam, J. (I969). Commitment to sporulation in Bacillus subtilis and its relationship to development of actinomycin resistance. Biochemical Journal II3, 29-37. 